Revista Brasileira de Cartografia

ISSN 1808-0936 | https://doi.org/10.14393/revbrascartogr

Sociedade Brasileira de Cartografia, Geodésia, Fotogrametria e Sensoriamento Remoto

\title{
O Dia do Cartógrafo, a Reforma do Calendário e a Primeira Medição de Latitude no Brasil
}

\author{
Cartographer's Day, Calendar Reform and the First Latitude Measurement in Brazil
}

Jorge Pimentel Cintra ${ }^{1}$ e Alexandre Pimentel Cintra ${ }^{2}$

1 Universidade de São Paulo, Museu Paulista da USP, DAC, São Paulo, Brasil, jpcintra@usp.br

ORCID: https://orcid.org/0000-0002-1369-6110

2 Fundação Getúlio Vargas, EASP, São Paulo, Brasil, alexcintra10@gmail.com

ORCID: https://orcid.org/0000-0001-9061-2024

Recebido: 03.2020 | Aceito: 05.2020

\begin{abstract}
Resumo: No presente trabalho analisa-se a definição do dia 6 de maio como sendo o Dia do Cartógrafo e a observação astronômica de latitude que deu origem a essa data, ocorrida em 27 de abril de 1500, no calendário juliano, antes da reforma gregoriana. Para isso, estuda-se tanto essa reforma do calendário como a observação astronômica, relatada na Carta do Mestre João. As contribuições principais foram duas: mostrou-se que o dia 27 de abril corresponde, no calendário juliano, ao dia 7 e não ao 6 de maio e avaliou-se a precisão tanto das tabelas de Abraão Zacuto utilizadas no cálculo como da medição de campo.
\end{abstract}

Palavras-chave: Dia do cartógrafo. Reforma gregoriana. Carta do Mestre João. História da Cartografia no Brasil.

Abstract: This paper analyzes the definition of May 6 as the Cartographer's Day and the astronomical observation of latitude that gave rise to this date, which took place on April 27, 1500, in the Julian calendar, before the Gregorian Reformation. For this, we study both this calendar reform and the astronomical observation, reported in Master John's Letter. The main contributions were two: it was shown that the 27th of April, corresponds in the Julian calendar to the 7th and not to the 6th of May, and the accuracy evaluation of both the tables used, by Abraão Zacuto, and the field measurement.

Keywords: Cartographer's Day. Gregorian Reform. Letter from Master John. History of Cartography in Brazil.

\section{INTRODUÇÃo}

Celebra-se a 6 de maio o Dia do Cartógrafo, instituído pela Sociedade Brasileira de Cartografia (SBC) após analisar diversas sugestões para a escolha da data ideal (SBC, 1973). O motivo foi ter sido esse o dia do primeiro trabalho cartográfico registrado no Brasil. Trata-se da determinação da latitude em Porto Seguro feita por três pilotos da frota de Cabral, sendo que um deles, conhecido como Mestre João, registrou o fato e sua carta não se perdeu. A fundamentação técnica dessa escolha baseia-se nas notícias fornecidas pelo coronel engenheiro Joaquim Francisco Duarte (1955).

No presente trabalho, tendo em conta a época, a expressão latitude refere-se ao que hoje se denomina latitude astronômica, pois se faz por visada a um astro (o Sol) e utilizando como referência a vertical do local determinada pela força da gravidade que atua sobre o astrolábio, pendurado sobre uma argola.

A observação ocorreu a 27 de abril de 1500, quando estava vigente o calendário juliano, mas tendo em conta a supressão de 10 dias do calendário, ocorrida de 4 ( $5^{\text {a }}$ feira) para 15 de outubro ( $6^{\mathrm{a}}$ feira) de 1582 , o referido coronel faz a seguinte observação: "vigorava na época o calendário juliano, e o atraso do ano civil sobre o ano trópico, que em 1582, quando da reforma gregoriana era de 10 dias, orçava aproximadamente em 9 dias em 1500. Em consequência, a declinação do Sol a procurar deve ser, não a de 27 de abril, mas a de 6 de maio de 1.500". Assim, a SBC resolveu adotar o dia 6 de maio (que seria o dia correspondente à medição num calendário gregoriano retroagido para antes da reforma) como a data em que seria comemorado o Dia do 
Cartógrafo. Nessa transformação foram suprimidos 9 dias, talvez fazendo uma conta de proporcionalidade. Como se mostrará, o atraso não "orçava aproximadamente 9 dias", mas era de 10 dias, quantidade que deveria ter sido suprimida.

Para mostrar isso analisou-se a reforma gregoriana do calendário. Depois estudou-se a referida Carta do Mestre João e, em decorrência, tratou-se da precisão da medida efetuada, coisa que, até o presente momento, não havia sido feito, ao que se conhece.

Nesses estudos recorreu-se a fontes primárias, isto é cópia de documentos originais disponíveis em repositórios digitais, da Torre do Tombo, de bibliotecas digitais da Espanha e de Portugal, para evitar erro de cópias, transcrições e traduções. Ao mesmo tempo, recorreu-se a modernas calculadoras siderais como a da NOAA e outras, para calcular valores mais precisos que servissem de referência.

\section{A REFORMA GREGORIANA E O DIA DO CARTÓGRAFO}

A reforma levada a cabo pelo Papa Gregório XIII visava resolver um conhecido problema do calendário juliano que, ao não estimar de maneira suficientemente precisa a duração do ano, fez com que o início real das estações, do ponto de vista astronômico, ocorresse cada vez mais cedo em relação ao previsto no calendário civil/eclesiástico. Assim, na época dessa reforma (1582), como se mostrará adiante, o equinócio astronômico da primavera no hemisfério norte ocorreu no dia 11 de março, 10 dias antes do equinócio da primavera eclesiástica, que havia sido fixado em 21 de março pelo Concílio de Nicéia em 325 d.C. Uma boa referência para essa reforma é Rio (1790).

A fixação do equinócio influenciava, entre outras coisas, a data da Páscoa, e mais tarde a Semana Santa, a Quaresma, o Carnaval e o Corpus Christi, já que o primeiro desses eventos, que determina os demais, está associado, na tradição judaico-cristã, à primeira lua cheia do mês de Nissan, mês que começa com o equinócio de primavera no hemisfério norte, em torno do dia 21 de março. Falando com precisão, a Páscoa cristã ocorre no $1^{\circ}$ Domingo, depois da lua cheia pascal que ocorre em ou após o dia 21 de março, data fixada por convenção e conveniência como início da primavera para fins de calendário litúrgico. Assim, a lua cheia "eclesiástica" é calculada por fórmulas ou tabelas de modo convencional que tentam se aproximar da lua cheia astronômica.

Dessa forma, esse plenilúnio indissociável da festa (em 325 d.C.), já não estava ocorrendo em sincronia, em função desses 10 dias de diferença acumulados após séculos, causando também um incômodo social, com o avanço das estações em relação à data do calendário civil.

Para explicar a origem dessa defasagem deve-se ter em conta a duração do ano, que já nas civilizações egípcia, babilônica e maia, era estimado em torno de 365 dias. Mas o acúmulo de frações já incomodava e causava perplexidades. O calendário juliano, promovido por Júlio César em 45 a.C., teve que inserir 67 dias para acertar o ano com o ciclo das estações e fixou a duração do ano em 365 dias e 1/4.

Com isso, a cada ano, há um excesso de 1/4 de dia e, para corrigir esse efeito, programou-se no calendário a inclusão de um dia a mais a cada quatro anos, inserindo esse dia em fevereiro nos chamados anos bissextos. A origem desse termo deve-se ao fato de a regra prever que o sexto dia antes das calendas de março fosse repetido com periodicidade quadrienal, e assim era chamado ante diem bis sextum Kalendas Martius. Ou seja, após o dia 24 introduziu-se o 24bis. Posteriormente esse dia extra foi transferido para o final do mês, gerando o 29 de fevereiro.

Mas acontece que a duração do ano não é exatamente 365,25 dias, mas aproximadamente 365,24219 ou 365 dias, 5 horas, 48 minutos e 45 segundos. Essa é a duração do chamado Ano Trópico, que também tem uma pequena variação. Seu cálculo pode ser feito por uma calculadora sideral, por exemplo, Time and Data (2020). Essa diferença anual (11 minutos e 15 segundos), acumulada por séculos gera também uma defasagem. Em 1545 anos (de 45 a.C. a 1500) a diferença de 0,0078125 de dia gerou 12,0703125 dias, ou 12,07 dias aproximadamente.

O Papa Gregório XIII, resolveu enfrentar a questão que já era muito debatida desde a antiguidade e acentuou-se no Concílio de Trento (finalizado em 1563), que delegou ao papa a solução desse problema. Tratava-se de uma questão complexa de astronomia e de medição precisa da duração do ano, da data do equinócio e de cálculos do ciclo lunar. O Papa encomendou essa tarefa a matemáticos e astrônomos, entre eles 
Christopher Clavius, Ignazio Danti e Aloisius Lilio. Foi desse último a proposta aceita por ser mais prática. Depois de muitos estudos e de consultas a matemáticos e príncipes, pois a mudança afetava também a vida civil, o papa promulgou a 25 de fevereiro de 1582, a bula Inter gravíssimas (Gregório XIII, 1582), definindo o 15 de outubro como primeiro dia desse novo calendário.

Como se lembra nesse texto, já desde o Concílio de Nicéia $(325 \mathrm{dC})$ se determinavam os passos para o cálculo da data da Páscoa: fixar o equinócio vernal por convenção no dia 21 de março (sendo que de fato está sempre bem próximo); identificar o $14^{\circ}$ dia da lua, correspondendo à lua cheia desse primeiro mês do ano, que pode ocorrer no dia do equinócio ou após ele e fixar a festa da Páscoa no primeiro domingo depois dessa lua cheia pascal. Uma vez fixado o equinócio, os cálculos referentes aos ciclos da lua e a data da Páscoa faziamse e ainda se fazem, mediante fórmulas ou tabelas práticas, envolvendo os conceitos de letra dominical, número áureo, calendas, epactas e outras variáveis que não são do caso detalhar.

Para refinar o ajuste de pequenas diferenças, prevendo o futuro, a Bula previu que não seriam bissextos os anos múltiplos de $100(1700,1800,1900, \ldots)$, a menos dos múltiplos de $400(1600,2000,2400, \ldots)$. Isso guarda um certo paralelismo com a aproximação de funções por meio de séries em que se alternam termos positivos e negativos, de valor cada vez menores, em módulo. Com essas regras não será necessária uma nova mudança tão cedo: por meio de cálculos em planilhas e calculadoras disponíveis na internet, pode-se mostrar que a prática de suprimir 3 dias (bissextos) a cada 400 anos consegue acertar os cálculos. Uma conta ilustrativa é olhar o que ocorre a cada 400 anos, chegando-se à seguinte duração para o ano médio gregoriano (AG) e sua diferença $(\triangle \mathrm{A})$ para o ano trópico (AT). As Eq. (1), (2) e (3), resumem os cálculos.

$$
\begin{aligned}
& \mathrm{AG}=365+1 / 4-1 / 100+1 / 400=365+97 / 400= \\
& 365,2425 \text { dias } \\
& \mathrm{AT}=365,242190 \text { dias } \\
& \Delta \mathrm{A}=\mathrm{AG}-\mathrm{AT}=-0,00031 \text { dias }
\end{aligned}
$$

Como decorrência, para produzir o erro de um dia (24h) são necessários 3225 anos. Ou seja, há tempo mais do que suficiente para se pensar na inserção ou supressão de mais um ano bissexto, no momento oportuno.

Para definir a época em que os 10 dias iriam ser retirados, a Bula escolheu um período em que havia menos festas de santos a serem comemoradas, recaindo a escolha nos dias de 5 a 14 de outubro de 1582 (incluindo os dois extremos) preservando assim a festa de São Francisco de Assis (4 de outubro). Como detalhe anedótico, Santa Teresa de Ávila faleceu na madrugada de 4 para 15 de outubro desse ano, e sua festa, mais tarde, para evitar a coincidência com a de São Francisco de Assis, foi fixada para o dia 15. A Bula preocupouse também em como acertar o pagamento dos operários com a supressão desses 10 dias, não trabalhados.

Tendo em conta o caráter mais ou menos convencional da data comemorativa, não haveria a necessidade de avançar o dia do cartógrafo para maio, assim como não há necessidade de mudar a data da descoberta do Brasil, podendo permanecer no 22 de abril e o mesmo se diga para todos os eventos significativos anteriores a 1582. Mas, postos a fazer mais um exercício astronômico, ocorreu aos que definiram o Dia do Cartógrafo, a ideia de retroagir o calendário gregoriano para 1500. Isso deveria ter sido feito seguindo a lógica do gregoriano, estabelecendo a correspondência dia a dia, coisa que se fará a seguir, mostrando que deveriam ser 10 e não 9 os dias a serem suprimidos, em 27 de abril de 1500, chegando-se ao dia 7 de maio e não ao 6 .

Aplicando uma lógica simples, mas equivocada, de uma regra de três, chega-se realmente a 9 dias, pois se a 1627 anos (de 45 a.C. a 1582) correspondem 10 dias, a 1545 anos (de 45 a.C. a 1500) correspondem 9,49 dias, que arredondados iriam para 9. Mas a falha do raciocínio é supor que em 45 a.C. não havia defasagem entre o equinócio astronômico e o dia 21 de março. A diferença, como se mostrará por cálculos e com a comprovação em uma calculadora sideral (por exemplo: TIME AND DATE, 2020 ou FOURMILAB, 2020), flutuava em dois dias, ou seja, em torno do dia 23 de março, como se pode ver nas Figuras 1 e 2, em função dos anos bissextos, local da Terra e outros fatores. Por exemplo, entre os anos 1 e 10, em oito anos ocorreu no dia 23 de março (diferença de dois dias), e duas vezes no dia 22 de março (diferença de 1 dia).

Estimando-se em 2 dias a defasagem na época de Júlio César e somando os 10 dias da reforma gregoriana, chega-se a 12 dias, valor que coincide com os 12,07 dias do cálculo feito anteriormente.

Para provar que se deve suprimir 10 e não 9 dias, serão seguidos dois caminhos. O primeiro, mais 
direto, consiste em utilizar uma calculadora. A Fourmilab (2020) transforma data juliana em gregoriana, direto e mostra que 27 de abril de 15.000 corresponde a 7 de maio desse ano; já a Time and date (2020) mostra que em 1.500 o equinócio caiu no dia 11 de março (calendário juliano), quando deveria ser no dia 21 desse mês (supressão de 10 dias). Com os dados dessa calculadora, exportados para uma planilha, foi possível montar um gráfico das diferenças e estudar seu comportamento desde o ano 1 até 1691 e gerou-se o gráfico da Figura 1.

Pode-se ver nessa figura e na planilha com o dado de cada ano, que do ano 1 ao ano 71 há uma flutuação da diferença entre -2 e -1, refletido em linhas vermelhas quase verticais, formando visualmente um retângulo vermelho; depois há uma estabilidade da diferença no valor -1, caracterizado por um trecho horizontal, do ano 72 ao 107. A seguir a oscilação se dá entre -1 e 0 (de 108 a 199), seguido de novo trecho horizontal (200 a 235). E esse padrão se repete. Passa pelo 0 e oscila entre 0 e 1 nos anos 236 e 327 (no ano do Concílio de Nicéia, 325, a diferença era de 1 dia, como se apontou). Nessa toada, a linha do gráfico atinge pela primeira vez o valor de 10 dias em 1392, oscila entre 10 e 9, para depois estabilizar em um patamar de 10 dias (entre 1488 e 1523), oscila de 10 para 11; cai para zero em 5 de outubro de 1582 com a reforma gregoriana e finalmente vai oscilando entre 0 e 1 e a seguir entre 1 e 2. Desse gráfico, com a ampliação na Figura 2, se segue que em 1500 a diferença era de 10 dias, valor a ser suprimido (e não 9) na lógica de transformar o dia do cartógrafo para o calendário gregoriano.

Figura 1 - Defasagem entre o equinócio vernal e o dia 21 de março, ano a ano, de 1d.C até 1681.

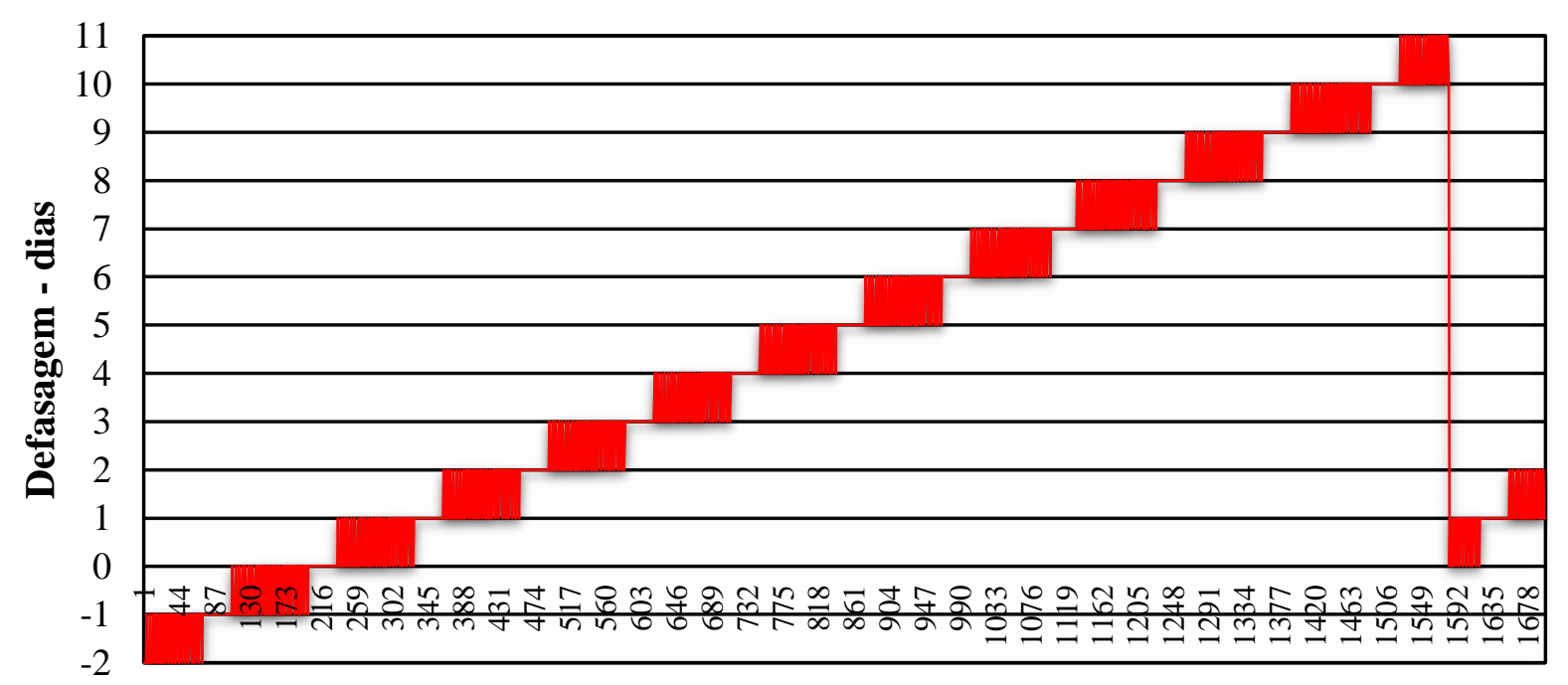

Ano

Fonte: Os autores (2020).

Outra forma de calcular os dias a serem suprimidos, sem necessidade da calculadora, mas só com a ajuda de uma planilha para organizar os dados, é retroagir o calendário gregoriano, ano a ano, obedecendo suas leis de formação, principalmente quanto aos anos bissextos e ir calculando sua diferença para com o juliano. Para isso, montou-se a Tabela 1, na qual se vai retroagindo as datas, de 4 de outubro de 1582 (último dia do calendário juliano) até 19 de abril de 1500 (data da Páscoa anterior à descoberta do Brasil), incluindo, o dia da medição. 
Figura 2 - Defasagem entre o equinócio vernal e o dia 21 de março, ano a ano, de 1.400 a 1600 d.C.

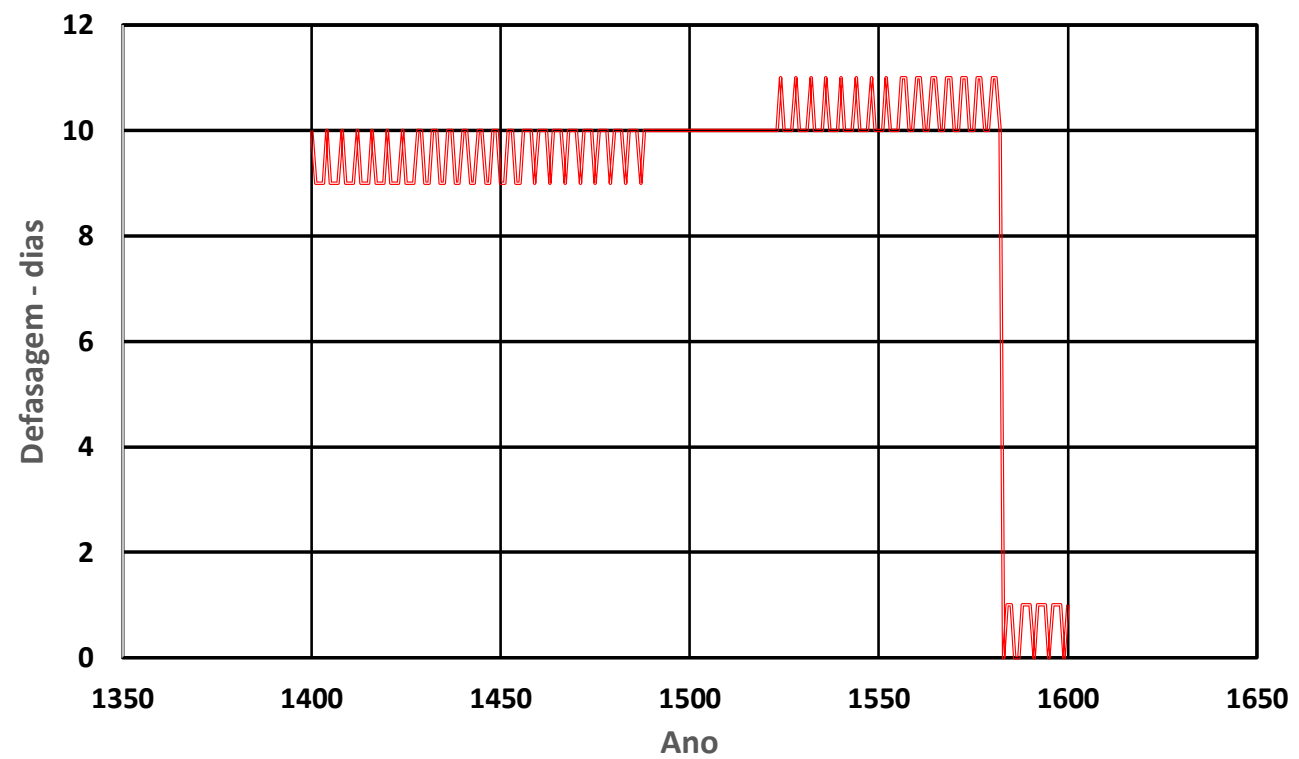

Fonte: Os autores (2020).

Na Tabela 1, N é o número de cada linha da tabela, tendo sido ocultadas as linhas de 10 a 82 . Evento é uma ocorrência de destaque nesse período, para a finalidade de interesse. Dias é o número de dias a serem subtraídos da linha anterior, da mesma coluna para obter a Data Juliana. O dia da semana é o mesmo para as duas Datas (dois calendários) e o número 1 na coluna Bissexto indica que na coluna Dias deve constar 366 e não 365. Em todo esse período (1582-1500) não há diferença entre os dois calendários quanto aos anos bissextos e assim a diferença entre as datas (subtração das colunas correspondentes) é constante e igual a 10. Mas esse número iria para 9 se fosse retroagido a uma data anterior a 1 de março de 1500, pois o dia anterior seria bissexto no juliano, mas não no gregoriano retroagido.

Para entender melhor deve-se seguir a marcha dos cálculos. A conta é feita dia a dia, retroagindo inicialmente de 4 a 1 de outubro; depois subtraem-se 273 dias, que correspondem aos meses de setembro a janeiro de 1582, para chegar à data de 1 de janeiro de 1582 (linha 5). Depois (linha 6 a 86) subtraem-se anos inteiros (365 ou 366 dias, respeitando a regra dos bissextos), até chegar a 1 de janeiro de 1501. Depois subtraem-se 245 dias, que correspondem aos meses de dezembro a maio de 1500, retroagindo-se, portanto, a 1 de maio de 1500 e, finalizando, subtrai-se sequencialmente 1 dia, desde essa data até a Páscoa em 19 de abril.

Assim, a Páscoa de 1500 (linha 99) caiu no dia juliano 19 de abril equivalente ao dia 29 de abril, no gregoriano retroagido, sendo um Domingo, por definição. A descoberta do Brasil, 22 de abril (linha 96), seria 2 de maio (quarta-feira) no gregoriano retroagido. Já a linha 91, correspondente ao dia da medição da latitude (segunda-feira, 27 de abril de 1500, no juliano), definido como Dia do Cartógrafo, equivale ao dia 7 de maio e não ao 6 de maio, no gregoriano retroagido. Por outro lado, como se disse, essa conta confere com a correlação que fazem calculadoras disponíveis na internet, para encontrar a equivalência entre juliano e gregoriano, por exemplo Fourmilab (2020). Um raciocínio adicional, que reforça, é verificar que nesse período (abril de 1500 a outubro de 1582), não houve nenhum bissexto secular e, portanto, as regras de acréscimo de dias são iguais nos dois calendários, e a diferença se mantem constante em 10 dias.

Pelos dois caminhos chega-se à conclusão de que se deve subtrair 10 dias e não 9. Mas, apesar da conta equivocada, dado o caráter relativamente convencional da data, não há ganho em mudar o dia do cartógrafo para o dia 7 de maio, sendo que o dia 6 já é tradicional. Não obstante, o cálculo correto da data correspondente (juliano $\mathrm{x}$ gregoriano retroagido) deve ser observado para estimar a declinação do Sol em datas anteriores à da reforma do calendário gregoriano, e, particularmente, quando se quer analisar os cálculos feitos nessa primeira operação cartográfica em solo brasileiro, como se fará a seguir. 
Tabela 1 - Equivalência entre os calendários juliano e gregoriano retroagindo.

\begin{tabular}{|c|c|c|c|c|c|c|c|c|c|c|}
\hline $\mathbf{N}$ & Evento & Dias & \multicolumn{3}{|c|}{ Data Juliana } & Dia da Semana & Bissexto & \multicolumn{3}{|c|}{ Data Gregoriana } \\
\hline 1 & Último dia Juliano & -1 & 4 & Out & 1582 & Quinta & - & 14 & Out & 1582 \\
\hline 2 & & -1 & 3 & Out & 1582 & Quarta & - & 13 & Out & 1582 \\
\hline 3 & & -1 & 2 & Out & 1582 & Terça & - & 12 & Out & 1582 \\
\hline 4 & & -1 & 1 & Out & 1582 & Segunda & - & 11 & Out & 1582 \\
\hline 5 & & -273 & 1 & Jan & 1582 & Segunda & - & 11 & Jan & 1582 \\
\hline 6 & & -365 & 1 & Jan & 1581 & Domingo & - & 11 & Jan & 1581 \\
\hline 7 & & -366 & 1 & Jan & 1580 & Sábado & 1 & 11 & Jan & 1580 \\
\hline 8 & & -365 & 1 & Jan & 1579 & Quinta & - & 11 & Jan & 1579 \\
\hline 9 & & -365 & 1 & Jan & 1578 & Quarta & - & 11 & Jan & 1578 \\
\hline 83 & & -366 & 1 & Jan & 1504 & Terça & 1 & 11 & Jan & 1504 \\
\hline 84 & & -365 & 1 & Jan & 1503 & Domingo & - & 11 & Jan & 1503 \\
\hline 85 & & -365 & 1 & Jan & 1502 & Sábado & - & 11 & Jan & 1502 \\
\hline 86 & & -365 & 1 & Jan & 1501 & Sexta & - & 11 & Jan & 1501 \\
\hline 87 & $1^{\circ}$ de maio de 1500 & -245 & 1 & Mai & 1500 & Sexta & - & 11 & Mai & 1500 \\
\hline 88 & & -1 & 30 & Abr & 1500 & Quinta & - & 10 & Mai & 1500 \\
\hline 89 & & -1 & 29 & Abr & 1500 & Quarta & - & 9 & Mai & 1500 \\
\hline 90 & & -1 & 28 & Abr & 1500 & Terça & - & 8 & Mai & 1500 \\
\hline 91 & Medição Latitude & -1 & 27 & Abr & 1500 & Segunda & - & 7 & Mai & 1500 \\
\hline 92 & & -1 & 26 & Abr & 1500 & Domingo & - & 6 & Mai & 1500 \\
\hline 93 & & -1 & 25 & Abr & 1500 & Sábado & - & 5 & Mai & 1500 \\
\hline 94 & & -1 & 24 & Abr & 1500 & Sexta & - & 4 & Mai & 1500 \\
\hline 95 & & -1 & 23 & Abr & 1500 & Quinta & - & 3 & Mai & 1500 \\
\hline 96 & Descobrimento do Brasil & -1 & 22 & Abr & 1500 & Quarta & - & 2 & Mai & 1500 \\
\hline 97 & & -1 & 21 & Abr & 1500 & Terça & - & 1 & Mai & 1500 \\
\hline 98 & & -1 & 20 & Abr & 1500 & Segunda & - & 30 & Abr & 1500 \\
\hline 99 & Páscoa de 1500 & -1 & 19 & Abr & 1500 & Domingo & - & 29 & Abr & 1500 \\
\hline
\end{tabular}

Fonte: Os autores (2020).

\section{A MEDIÇÃO DO DIA 27 DE ABRIL DE 1500}

É também interessante acompanhar a medição de latitude em Porto Seguro. A fonte primordial é a chamada carta de Mestre João, documento que sobreviveu junto com a carta de Pero Vaz de Caminha e mais uma outra, a carta do Piloto anônimo. Uma tradução dessas cartas, com comentários e ampla bibliografia, pode ser encontrada em Pereira (1999). Para a Carta de Mestre João pode-se ver Oliveira (1980), que, além de uma tradução, reproduz o documento original, disponível na Torre do Tombo (2020), e que é mostrado em miniatura na Figura 3.

Esse original foi encontrado por Francisco Adolfo de Varnhagen no arquivo da Torre do Tombo (Portugal), e publicado na Revista do Instituto Histórico e Geográfico Brasileiro (1834). O primeiro parágrafo trata da medição astronômica da latitude e assim, a seguir foi feita a tradução desse parágrafo, atualizando a grafia, a pontuação e vertendo para o português quando necessário, pois o autor era de origem castelhana e misturava os idiomas. O sinal / indica mudança de linha e // corresponde a mudança de parágrafo. Os números colocados entre colchetes são referências para os comentários posteriores. 
Figura 3 - Original da Carta de Mestre João, notando-se o carimbo da Torre do Tombo.

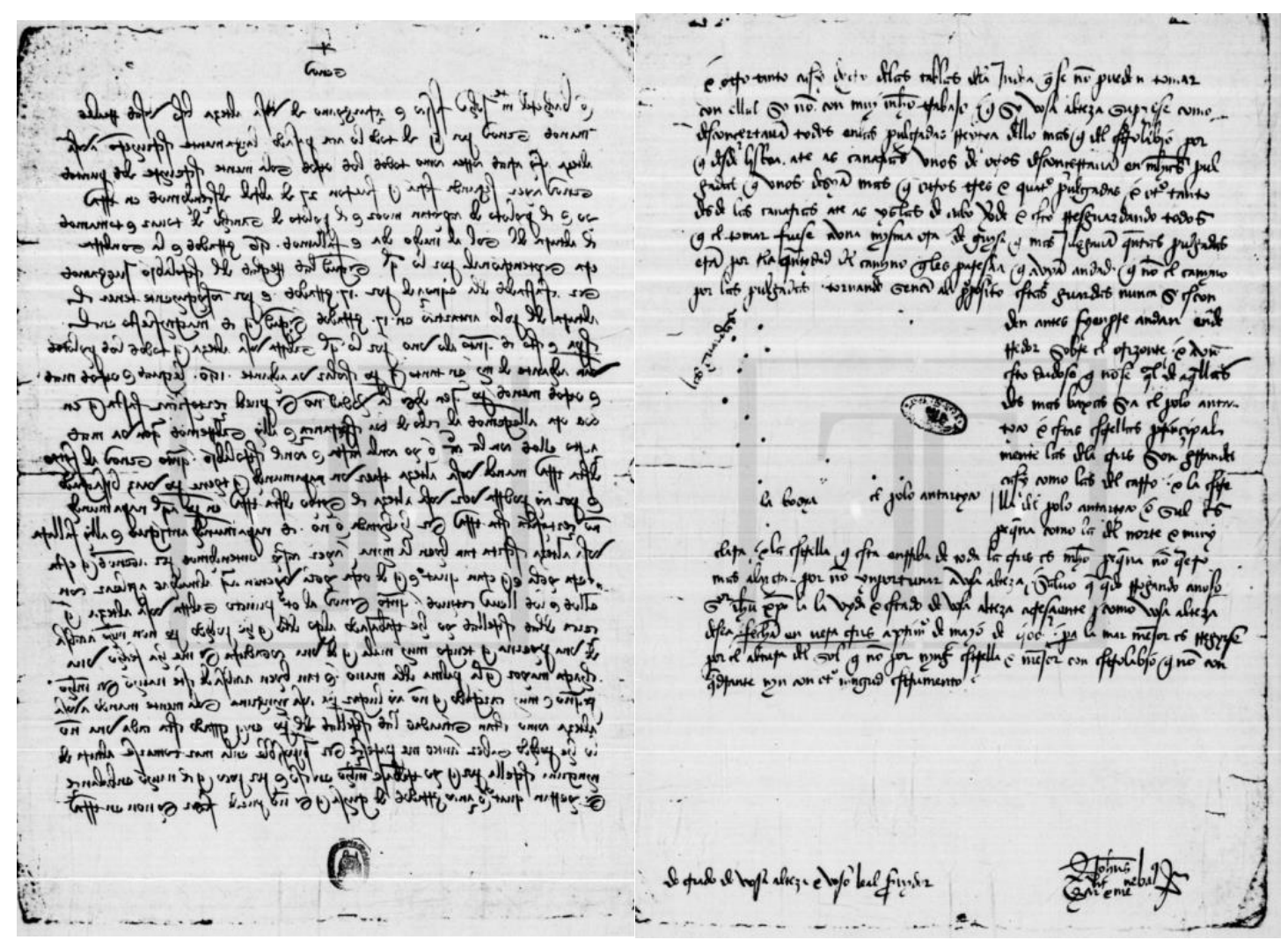

Fonte: Torre do Tombo (2020).

\section{Señor}

O bacharel mestre João, médico e cirurgião de Vossa Alteza; beijo vossas reais / mãos. Senhor: como, de tudo o aqui acontecido, longamente escreveram a Vossa / Alteza, assim Aires Correa [1] como todos os outros, somente escreverei (sobre) dois pontos. // Senhor: ontem, segunda-feira, que foram 27 de abril [2], descemos em terra / eu e o piloto do capitão-mor e o piloto de Sancho de Tovar [3] e tomamos / a altura do Sol ao meio-dia e achamos 56 graus, e a sombra / era setentrional [4], pelo que, segundo as regras do astrolábio [5], julgamos / estar afastados da equinocial por $17^{\circ}$, e por conseguinte estar a / altura do pólo antártico em $17^{\circ}$, segundo é manifesto na / esfera [5].

\subsection{Comentários históricos}

São necessários alguns comentários para a compreensão desse trecho em que se fala da medição da latitude. O trecho [1] menciona-se Aires Correa, que seria o responsável pela feitoria a ser instalada em Calicute na Índia; depois de instalada, a feitoria foi destruída por comerciantes árabes e foram mortos diversos portugueses, entre eles Pero Vaz de Caminha e o próprio Aires Correa. Em [2], a referência a ontem, que foram 27 de abril, segunda-feira confirma os cálculos feitos na Tabela 1, quanto ao dia da semana. Em [3] pode-se completar dizendo que o piloto do Capitão-mor (Pedro Álvares Cabral) chamava-se Afonso Lopes e o piloto de Sancho de Tovar (que era o Sota-capitão, ou sub-comandante) chamava-se Pedro Escobar, dados que se obtém da carta de Pero Vaz de Caminha.

Antes de iniciar as explicações, vale dizer que há bons textos de referência, ainda que incompletos ou pouco detalhados nos aspectos e ângulos aqui apresentados, por exemplo: Moraes (1984) e Silva (1922).

\subsection{A medição da altura do sol}

Em [4] relata-se a medição feita: "Tomamos a altura do Sol ao meio dia e achamos 56 graus e a sombra era setentrional". Por sua vez [5] declara que o equipamento utilizado para medir a altura do Sol era o 
astrolábio, instrumento utilizado desde a antiguidade e aperfeiçoado pelos portugueses, que o empregaram desde 1420, ou seja, desde o princípio das grandes navegações. Na Figura 4 mostra-se um deles, para entender o princípio de funcionamento.

Figura 4 - Astrolábio para a medição da altura do Sol.

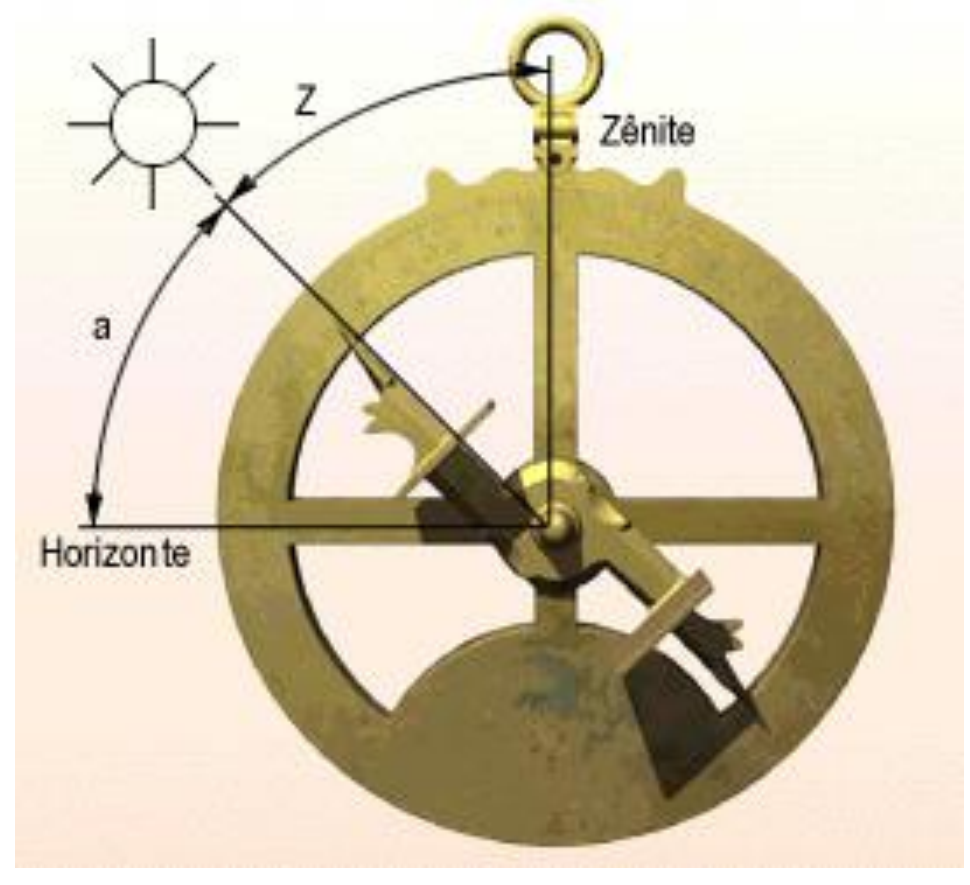

Fonte: MEGA ARQUIVO (2020).

Na figura 4, $a$ é a altura do Sol com relação ao horizonte e z é a distância zenital; a soma resulta em $90^{\circ}$. Pendurado pela argola superior, o equipamento, pela gravidade, posiciona-se com seus eixos nas direções vertical e horizontal. Os dois ponteiros, que formam uma só peça, podem ser movidos de tal forma que um raio do Sol passe pelos orifícios de duas placas solidárias aos ponteiros e nessa condição pode-se efetuar a leitura do ângulo $a$ no ponteiro superior sobre a escala circular graduada. Através do exame da precisão de mapas quinhentistas e seiscentistas, sabe-se que a leitura por interpolação sobre a graduação ia normalmente até $1 / 3$ de grau e a precisão média situava-se em torno de 0,5 grau. Veja-se, por exemplo, que a latitude da última capitania hereditária ao sul do Brasil, distribuída em 1535, era $28^{\circ}$ e $1 / 3$, e que a precisão média em latitude do Mapa de Luis Teixeira era de cerca de 0,5 ${ }^{\circ}$ (CINTRA, 2013 e 2015).

$\mathrm{O}$ fato da medição ser ao meio dia tem a sua razão de ser: nesse instante em que o Sol cruza o meridiano local, o triângulo esférico transforma-se em um arco e os cálculos simplificam-se muito, bastando realizar somas e subtrações. Conserva-se a informação de que o mestre José Vizinho, em torno de 1485, determinou a latitude da Guiné por meio desse processo, medindo a altura meridiana do Sol. Por outro lado, a afirmação de que a sombra era setentrional está equivocada: isso acontece no hemisfério norte, mas não no sul, e talvez essa frase foi redigida mais pelo costume do que pela observação direta: a sombra na realidade era sul. Isso se mostrará na Figura 9, no item 3.4.

\subsection{Cálculo da declinação do Sol no dia desejado}

Em [5] mencionam-se as regras do astrolábio e se faz referência à esfera. Isso remete às regras para efetuar os cálculos com os dados do astrolábio e obter a latitude do lugar. Para isso recorre-se ao Tratado da Esfera, que o autor abrevia para Esfera, de João de Sacrobosco, inglês que foi professor em Paris na primeira metade do século XIII e que escreveu essa obra em torno de 1220. Foi composto para aulas de astronomia, uma das disciplinas ensinadas nas universidades medievais. Serviu como base para a navegação marítima e cálculos astronômicos, primordialmente para a determinação da latitude (SACROBOSCO, 1991). 
Para essa determinação era necessário contar com uma tabela das declinações solares, que na época já tinham a precisão suficiente, como se mostrará. Elas figuram tanto no Almaque Perpétuo de Abraão Zacuto como no Regimento do Estrelábio e do Quadrante, conhecido também como Regimento de Munique, que embora publicado mais tarde, já circulava em cópias manuscritas. As regras presentes nessas obras também já se encontravam no Libro del saber de astronomia, de Afonso X, o sábio, escrito por volta de 1275. Mas quando os portugueses cruzaram o equador em direção ao sul, no ano de 1471, as regras tiveram que ser completadas para contemplar a nova situação.

A Figura 5 mostra o movimento aparente do Sol ao longo do ano. O Sol caminha ao longo do plano da eclíptica e cruza o plano do equador no ponto Áries $(\Upsilon)$, na trajetória ascendente no início do ano trópico (equinócio de março), depois segue pelos pontos 1, 2 e 3 (solstício de junho) e depois em movimento descendente passa por Libra $(\Omega)$, equinócio de setembro, entrando nos signos da banda do sul, na expressão utilizada nos textos da época. O ângulo $\varepsilon$ entre os dois planos é a obliquidade da eclíptica ou do eixo de rotação da Terra. A coordenada $\lambda$ é a longitude ou posição do Sol na eclíptica e $\delta$ é a declinação do Sol. Esta, medida na perpendicular ao equador, varia de $0^{\circ}$ a $+\varepsilon\left(23^{\circ} 27^{\prime}\right.$, aproximadamente) e cerca de seis meses depois vai a $-\varepsilon$, correspondendo ao momento dos dois solstícios (dezembro e junho). Em um movimento relativo, o Sol passa, ao longo do ano, pelas 12 constelações do zodíaco, fato que será útil para entender alguns cálculos e tabelas da época.

Para a determinação da latitude de um lugar é necessário conhecer previamente o valor da declinação no dia desejado. Hoje trabalha-se com fórmulas e aplicativos, mas na época, a maneira disponível era utilizar tabelas e fazer cálculos de interpolação. Vale apontar de passagem que resolvendo os triângulos esféricos retângulos da Figura 5 tem-se a seguinte regra que permite calcular $\delta$ em função de $\lambda$ : $\operatorname{sen} \delta=\operatorname{sen} \varepsilon$. $\operatorname{sen} \lambda$. Isso permite montar uma tabela de $\delta$ quando se conhece $\lambda$, coisa que fez Abraão Zacuto. Como exemplo desses triângulos esféricos, na figura 5, tem-se aqueles formados pelas posições do Sol, 1, 2,3, baixando a perpendicular até o equador, com ângulo $\varepsilon$, com lado no equador igual a $\mathrm{d}_{1}, \mathrm{~d}_{2}, \mathrm{~d}_{3}$ e longitude $\lambda$ medida ao longo da eclíptica.

Figura 5 - Coordenadas do Sol em seu movimento anual sobre a eclíptica.

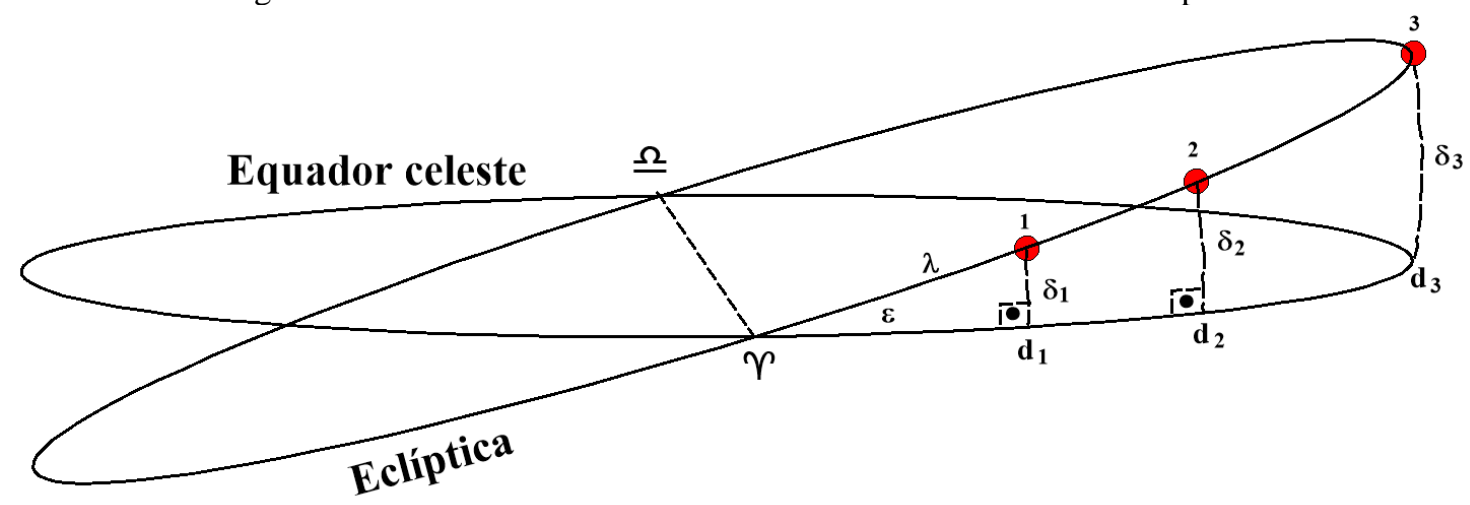

Fonte: Os autores (2020).

Como detalhe prático, para muitas aplicações, como por exemplo a construção de gráficos da trajetória aparente do Sol e estudo da insolação para determinado dia do ano, pode ser útil uma fórmula simplificada (Cooper, 1969), como a indicada em (4).

$$
\delta=-23,45^{\circ} \cdot \cos \left(\frac{360}{365} \cdot(N+10)\right)
$$

onde:

$\delta$ - declinação desejada, que sai com o sinal

A - constante $-23,45^{\circ}$ corresponde a $\varepsilon$, obliquidade da eclíptica ( $23^{\circ} 27^{\prime}$ )

$\mathrm{N}$ - número de dias do ano, transcorridos a partir de 1 de janeiro

Obs: o argumento do cosseno é expresso em graus e não em radianos

A Eq. (4) permite gerar um gráfico (Figura 6) para interpolação e uso nas aplicações mencionadas. Como se deduz, essa fórmula, genérica para qualquer local e dia do ano, não leva em conta os bissextos nem 
a hora do dia, adotando valores médios que são suficientes para as aplicações apontadas.

No entanto, para cálculos mais precisos, recomenda-se o uso da calculadora da NOAA (2020), que leva em conta os bissextos, o local (latitude e longitude), o fuso horário e outros dados.

Mas, como apontado, para calcular a declinação na época utilizavam-se tabelas, em concreto o Almanaque perpétuo de Abraão Zacuto, traduzido do hebraico para o latim por José Vizinho, editado em Leiria no ano de 1496. Tem como ano base ou raiz o ano de 1473 e é perpétuo por repetir-se em ciclos de 4 anos, levando em conta os bissextos. Ele está composto de 4 folhas e 8 tábuas (Solis de 1 a 4 e seus Resíduos). Existe uma tabela para cada ano do ciclo; assim de 1473 (ano zero, ou raiz, Tabula prima) até 1500 passaram-se 27 anos e portando deve-se usar a Tabula quarta, reproduzida na Figura 7. Começar pelo mês de março e terminar por fevereiro não é aleatório: isso serve para acrescentar, a cada 4 anos, o 29 de fevereiro no final da Tabula tertia; ou seja, esse acréscimo não fica no meio, mas no fim da tabela. Essas tabelas servem para iniciar o cálculo da longitude do Sol $(\lambda)$, que se passa a explicar.

Figura 6 - Gráfico da variação da declinação solar ao longo do ano, pela fórmula (4). Valores aproximados.

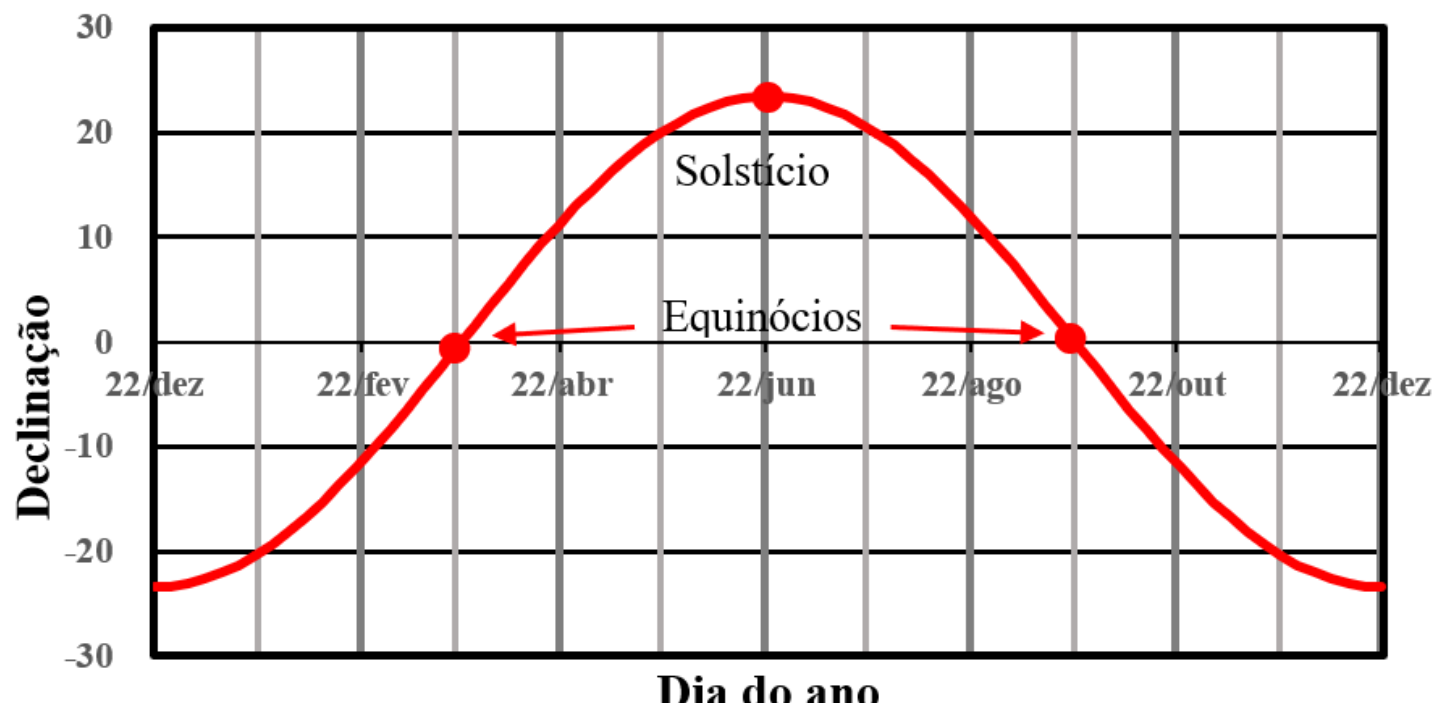

Fonte: Os autores (2020).

A primeira coluna (Dies) corresponde ao dia do mês. Na primeira linha, que é dupla, encontram-se os meses (de março a agosto) na linha superior, e os signos do zodíaco ou constelação em que se encontra o Sol (de Peixes a Leão), na linha inferior. Entrando nessa tabela com o dia 27 (primeira coluna, linha 27) e o mês de abril (coluna 2) chega-se ao valor: $\lambda_{0}=16^{\circ} 19^{\prime} 10^{\prime \prime}$. Para os cálculos seguintes é preciso saber em que signo está o Sol. Olha-se para o alto da coluna de abril e lê-se Aries (Carneiro), mas, nessa coluna, existe a mudança de signo, para Touro, denotado pelo símbolo dessa constelação в, colocado ao lado do dia 11. Assim, no dia 27 de abril o Sol já se encontra na segunda constelação do ano, e ao usar a tabela subsequente o valor deverá ser buscado na coluna 1, pois Carneiro corresponde a 0 .

Tendo $\lambda$ (longitude do Sol), o passo seguinte é determinar um acréscimo a esse valor devido ao tempo passado desde a data base da tabela. De 1473 até o ano em questão, 1500, são 6 ciclos completos. Então, consulta-se a Figura 8, tabela da direita que tem o nome de Tabula equationis solis, $1^{\text {a }}$ coluna de dados, e lêse o valor da linha 6 (grafada erroneamente como 9), obtendo-se o acréscimo $\Delta \lambda=0^{\circ} 10^{\prime} 36^{\prime \prime}$, que somado ao valor anterior leva a $\lambda=16^{\circ} 29^{\prime} 46^{\prime}$, ou aproximadamente $16^{\circ} 30^{\prime}$, que é a longitude do Sol nesse dia (juliano). 
Zabula quarta folis

\begin{tabular}{|c|c|c|c|c|c|c|}
\hline & mazti? & aptlis & mais & 3ูun? & 7ुnali & anguft \\
\hline 胥 & pilces & aries & tant 9 & getnini & cancez & leo \\
\hline & है iil ₹ & $\bar{g}$ in ह & โ & ğ & $\bar{g} \mathrm{~m}$ & $\bar{g} \operatorname{tm} 2$ \\
\hline 2 & $\begin{array}{lll}20 & 42 & 42 \\
21 & 42 & 11 \\
\end{array}$ & $\begin{array}{|ccc|}21 & 16 & 55 \\
22 & 8 & 19 \\
\end{array}$ & $\begin{array}{|lll|}20 & 6 & 48 \\
21 & 4 & 17 \\
\end{array}$ & $\mid \begin{array}{lll}19 & 40 & 38 \\
20 & 37 & 39\end{array}$ & $\begin{array}{|ccc|}18 & 11 & 26 \\
19 & 8 & 29 \\
\end{array}$ & $\begin{array}{|lll|}17 & 48 & 21 \\
18 & 46 & 0 \\
\end{array}$ \\
\hline $\begin{array}{l}3 \\
4 \\
\end{array}$ & $\begin{array}{rrr}22 & 41 & 40 \\
23 & 41 & 7\end{array}$ & $\begin{array}{|ccc|}23 & 6 & 43 \\
24 & 5 & 2\end{array}$ & \begin{tabular}{lll|l}
22 & 1 & 46 & 2 \\
22 & 59 & 15 & 2 \\
\end{tabular} & $\begin{array}{lll}21 & 34 & 41 \\
22 & 31 & 42\end{array}$ & $\begin{array}{lll}20 & 5 & 32 \\
21 & 2 & 37\end{array}$ & \begin{tabular}{rrr|}
19 & 43 & 39 \\
20 & 41 & 2 \\
\end{tabular} \\
\hline 5 & \begin{tabular}{lll|}
24 & 40 & 31 \\
25 & 39 & 56
\end{tabular} & $\left|\begin{array}{lll}25 & 3 & 21 \\
26 & 1 & 40\end{array}\right|$ & \begin{tabular}{lll|l}
23 & 57 & 43 & 2 \\
24 & 54 & 11 & 2 \\
\end{tabular} & 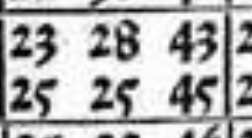 & \begin{tabular}{llll|}
21 & 59 & 41 & 2 \\
22 & 56 & 47 & 2 \\
\end{tabular} & $\begin{array}{|lrr|}21 & 39 & 2 \\
22 & 36 & 45 \\
\end{array}$ \\
\hline $\begin{array}{l}7 \\
8 \\
\end{array}$ & $\begin{array}{lll}26 & 39 & 20 \\
27 & 38 & 34 \\
\end{array}$ & $\begin{array}{lll}26 & 59 & 52 \\
27 & 59 & 52\end{array}$ & \begin{tabular}{lll|}
25 & 51 & 34 \\
26 & 48 & 57
\end{tabular} & $\begin{array}{lll}25 & 22 & 46 \\
26 & 19 & 47\end{array}$ & \begin{tabular}{lll|l}
23 & 53 & 54 & 2 \\
24 & 51 & 8 & 2 \\
\end{tabular} & $\begin{array}{|lll|}23 & 34 & 28 \\
24 & 32 & 18 \\
\end{array}$ \\
\hline $\begin{array}{l}9 \\
10\end{array}$ & $\begin{array}{lll}28 & 37 & 48 \\
29 & 37 & 1 \\
\end{array}$ & $\mid \begin{array}{rrr}29 & 58 & 2 \\
29 & 56 & 13\end{array}$ & $\begin{array}{|lll|}27 & 46 & 19 \\
28 & 43 & 39 \\
\end{array}$ & & $\begin{array}{|lll|}25 & 48 & 12 \\
26 & 45 & 24 \\
\end{array}$ & $\begin{array}{|rrr|}25 & 30 & 8 \\
26 & 27 & 59 \\
\end{array}$ \\
\hline $\begin{array}{l}\text { II } \\
12\end{array}$ & $\begin{array}{lll}0 & 37 & 0 \\
1 & 35 & 16\end{array}$ & $\mid \begin{array}{rrr}80 & 54 & 16 \\
1 & 52 & 15 \\
\end{array}$ & \begin{tabular}{lll|}
29 & 40 & 57 \\
10 & 38 & 16
\end{tabular} & $\begin{array}{ccc}29 & 10 & 53 \\
50 & 7 & 54\end{array}$ & $\begin{array}{lll}27 & 42 & 37 \\
28 & 39 & 49 \\
\end{array}$ & $\begin{array}{lll}27 & 25 & 51 \\
28 & 23 & 45 \\
\end{array}$ \\
\hline 13 & $\begin{array}{lll}2 & 34 & 22 \\
3 & 33 & 21\end{array}$ & $\left|\begin{array}{lll}2 & 50 & 23 \\
3 & 48 & 15\end{array}\right|$ & $\begin{array}{|lll|} & 35 & 32 \\
2 & 32 & 44 \\
\end{array}$ & \begin{tabular}{lll|l} 
& 4 & 55 & 2 \\
2 & 1 & 56 & 8 \\
\end{tabular} & \begin{tabular}{lll|}
29 & 37 & 3 \\
80 & 34 & 17
\end{tabular} & $\mid \begin{array}{lll}29 & 21 & 39 \\
\prod_{0} & 19 & 43\end{array}$ \\
\hline 15 & $\begin{array}{lll}4 & 32 & 19 \\
5 & 31 & 56\end{array}$ & \begin{tabular}{|lll}
4 & 46 & 16 \\
5 & 44 & 12
\end{tabular} & $\begin{array}{|rrr|}3 & 30 & 3 \\
4 & 27 & 14 \\
\end{array}$ & $\begin{array}{lll}2 & 58 & 57 \\
3 & 55 & 58 \\
\end{array}$ & \begin{tabular}{lll|}
1 & 31 & 36 \\
2 & 28 & 56 \\
\end{tabular} & $\begin{array}{|lll|}1 & 17 & 45 \\
2 & 15 & 50 \\
\end{array}$ \\
\hline $\begin{array}{l}17 \\
18\end{array}$ & \begin{tabular}{lll|} 
& 30 & 9 \\
7 & 29 & 1 \\
\end{tabular} & $\left|\begin{array}{rrr}6 & 42 & 2 \\
7 & 39 & 53\end{array}\right|$ & $\begin{array}{|lll|}5 & 24 & 26 \\
6 & 21 & 37 \\
\end{array}$ & \begin{tabular}{rrr|}
4 & 52 & 59 \\
5 & 50 & 0 \\
\end{tabular} & \begin{tabular}{lll|}
3 & 26 & 15 \\
4 & 23 & 36 \\
\end{tabular} & $\begin{array}{|rrr|}3 & 13 & 50 \\
4 & 12 & 3 \\
\end{array}$ \\
\hline $\begin{array}{l}19 \\
20 \\
\end{array}$ & $\begin{array}{|lll|}8 & 27 & 54 \\
9 & 26 & 40 \\
\end{array}$ & $\mid \begin{array}{lll}8 & 37 & 44 \\
9 & 35 & 29\end{array}$ & $\begin{array}{|lll|}7 & 13 & 45 \\
8 & 15 & 54 \\
\end{array}$ & $\begin{array}{|lll|} & 47 & 2 \\
7 & 44 & 4\end{array}$ & $\mid \begin{array}{lll}5 & 20 & 59 \\
6 & 18 & 19 \\
\end{array}$ & $\begin{array}{|ccc|}5 & 10 & 10 \\
6 & 8 & 29 \\
\end{array}$ \\
\hline $\begin{array}{l}21 \\
22 \\
\end{array}$ & \begin{tabular}{llll|}
10 & 25 & 25 \\
11 & 24 & 10 \\
\end{tabular} & $\mid \begin{array}{rrr}10 & 33 & 14 \\
11 & 30 & 59\end{array}$ & $\mid \begin{array}{ccc}9 & 13 & 3 \\
10 & 10 & 8\end{array}$ & $\begin{array}{|lll|}8 & 41 & 5 \\
9 & 38 & 6 \\
\end{array}$ & $\mid \begin{array}{lll}7 & 15 & 45 \\
8 & 13 & 13\end{array}$ & $\begin{array}{|llr|}7 & 6 & 48 \\
8 & 5 & 8 \\
\end{array}$ \\
\hline $\begin{array}{l}23 \\
24\end{array}$ & \begin{tabular}{lll|}
12 & 22 & 52 \\
13 & 21 & 33
\end{tabular} & $\mid \begin{array}{lll}12 & 28 & 38 \\
13 & 26 & 18 \\
\end{array}$ & $\begin{array}{lll}11 & 7 & 11 \\
12 & 4 & 15 \\
\end{array}$ & $\mid \begin{array}{rrr}10 & 35 & 8 \\
11 & 32 & 10\end{array}$ & $\left|\begin{array}{ccc}9 & 10 & 41 \\
10 & 8 & 9\end{array}\right|$ & $\begin{array}{ccc}9 & 3 & 30 \\
10 & 1 & 53 \\
\end{array}$ \\
\hline $\begin{array}{l}25 \\
26 \\
\end{array}$ & \begin{tabular}{lll|}
14 & 20 & 14 \\
15 & 18 & 49 \\
\end{tabular} & $\begin{array}{lll}14 & 23 & 58 \\
15 & 21 & 35\end{array}$ & $\left|\begin{array}{rrr}13 & 1 & 19 \\
13 & 58 & 22\end{array}\right|$ & $\mid \begin{array}{lll}12 & 29 & 12 \\
13 & 26 & 14\end{array}$ & \begin{tabular}{|rrr}
11 & 5 & 38 \\
12 & 3 & 7
\end{tabular} & $\mid \begin{array}{rrr}11 & 0 & 16 \\
11 & 58 & 45 \\
\end{array}$ \\
\hline $\begin{array}{l}27 \\
28 \\
\end{array}$ & \begin{tabular}{lll|}
16 & 17 & 24 \\
17 & 15 & 58 \\
\end{tabular} & $\mid \begin{array}{lll}16 & 19 & 10 \\
17 & 16 & 46\end{array}$ & $\mid \begin{array}{ccc}14 & 55 & 25 \\
15 & 52 & 28\end{array}$ & {$\left[\begin{array}{lll}14 & 23 & 16 \\
15 & 20 & 18\end{array}\right]$} & $\begin{array}{rrr}13 & 0 & 38 \\
13 & 58 & 9\end{array}$ & $\mid \begin{array}{lll}12 & 57 & 44 \\
13 & 55 & 45\end{array}$ \\
\hline $\begin{array}{l}29 \\
30 \\
\end{array}$ & $\begin{array}{rrr}18 & 14 & 29 \\
19 & 13 & 0 \\
\end{array}$ & $\left|\begin{array}{lll}18 & 14 & 16 \\
19 & 11 & 48\end{array}\right|$ & \begin{tabular}{lll|}
16 & 49 & 31 \\
16 & 46 & 34
\end{tabular} & $\begin{array}{rrr}16 & 17 & 2 \\
17 & 14 & 23\end{array} \mid$ & $\begin{array}{lll}14 & 55 & 41 \\
15 & 53 & 4\end{array}$ & $\begin{array}{rrr}14 & 54 & 17 \\
15 & 52 & 58 \\
\end{array}$ \\
\hline 31 & 201130 & 000 & $\left|\begin{array}{lll}18 & 46 & 37\end{array}\right|$ & 000 & $\mid \begin{array}{lll}16 & 50 & 47\end{array}$ & $\left|\begin{array}{lll}16 & 51 & 22\end{array}\right|$ \\
\hline
\end{tabular}

Fonte: Zacuto (1496).

O passo seguinte é calcular a declinação $\delta$ do Sol, em função da longitude $\lambda$, já determinada acima $\left(16^{\circ} 30^{\prime}\right)$. Isso se faz por uma interpolação linear na Tabela de declinação (Tabula declinationis), bloco da 
esquerda da Figura 8.

A primeira coluna (grado) corresponde a uma série de $\lambda$ inteiros. Para fazer a interpolação deve-se buscar a declinação das linhas de $\lambda=16$ e 17, na coluna correspondente à constelação em que se encontra o Sol na data em questão, que como se viu é Touro, coluna com o número 1 no topo.

Entrando nessa coluna, têm-se para $\lambda_{1}=16$ a declinação $\delta_{1}=16^{\circ} 42^{\prime}$ e para $\lambda_{2}=17$ a declinação $\delta_{2}=$ $17^{\circ} 0^{\prime}$. Para o valor de $\lambda=16^{\circ} 29^{\prime} 46^{\prime \prime}\left(16,4961^{\circ}\right.$, ou $\left.16,5^{\circ}\right)$, a declinação interpolada é $\delta=16^{\circ} 50^{\prime} 56^{\prime}$ ". Tendo em conta a aproximação com que se trabalha, pode-se arredondar para $16^{\circ} 51^{\prime}$. O texto de Mestre João indica $17^{\circ}$. Ou seja, arredondou 9' com relação à tabela.

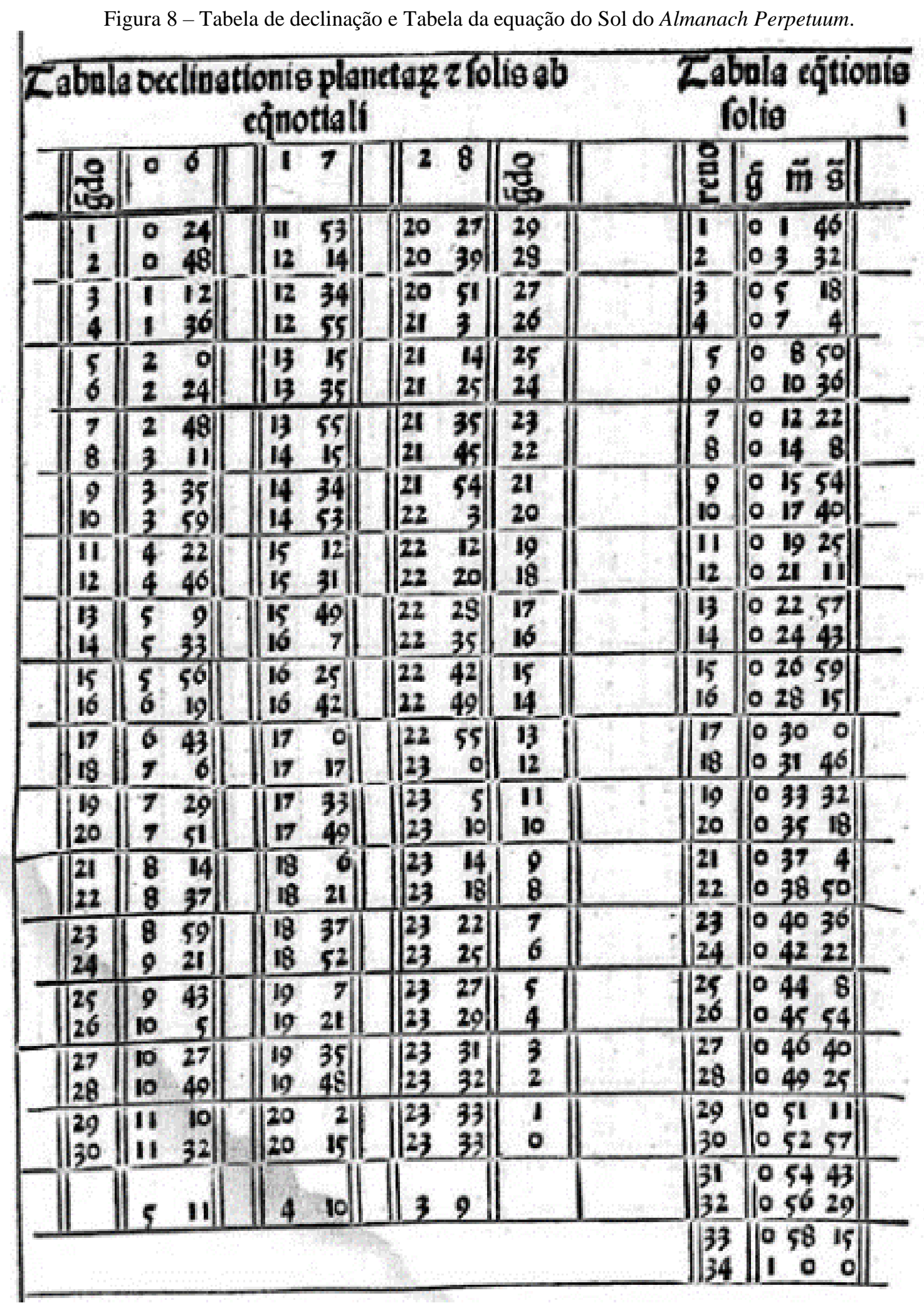

Fonte: Zacuto (1496). 


\subsection{As regras do astrolábio}

As Regras do astrolábio, em diversas versões, e o Tratado da esfera indicam os cálculos a serem feitos para obter a latitude do lugar. Assim, na versão do Regimento de Munique, para o hemisfério sul, a regra é: "E se o Sol estiver nos signos que são da banda do norte, tomarás a altura do Sol e a declinação daquele dia e ajuntarás tudo: o que der, tira-o de $90^{\circ}$, e o que ficar é o que estarás afastado da linha".

De acordo com a Figura 5, a 27 de abril o Sol já havia passado pelo ponto $\gamma$ e estava na trajetória ascendente, no signo de Touro, o segundo dos da "banda do norte". Portanto, a regra se aplica. Ela pode ser vista na Eq. (5).

sendo:

$$
\varphi=90^{\circ}-(\mathrm{a}+\delta)
$$

$\varphi$ - latitude do lugar, valor que se procura

a - altura do Sol medida com astrolábio, no caso, $56^{\circ}$

$\delta$ - declinação do Sol, calculada pelas tabelas, no caso, $16^{\circ} 51^{\prime}$, ou arredondando, $17^{\circ}$

Para entender teoricamente essa fórmula, desenhou-se a Figura 9 que é a clássica projeção do sol, para o dia da observação, no Plano Meridiano do Observador (PMO), que contem: o observador em O, o zênite Z e a linha Norte-Sul (N-S), que coincide na representação com o Plano do Horizonte do Observador (PHO).

Para construir essa figura começa-se por marcar o pólo sul PS, tendo em conta o fato da altura do pólo elevado ser igual à latitude do lugar $\varphi$. Isso permite desenhar a linha dos pólos, que une o pólo sul PS ao observador $\mathrm{O}$ e ao pólo norte PN (trecho fora da figura). A linha do Equador EQ é obtida tirando-se a perpendicular à linha dos pólos, passando por O. Pela geometria, o ângulo entre o Equador celeste (EQ) e o zênite também é igual a $\varphi$.

A partir do equador celeste (EQ), com centro em $\mathrm{O}$, marca-se o ângulo $\delta$ correspondente à declinação daquele dia e desenha-se o raio (tracejado na figura) até cruzar o PMO na posição do Sol, no momento da sua culminação (meio dia solar).

Figura 9 - Esquema da observação da latitude a 27 de abril de 1500.

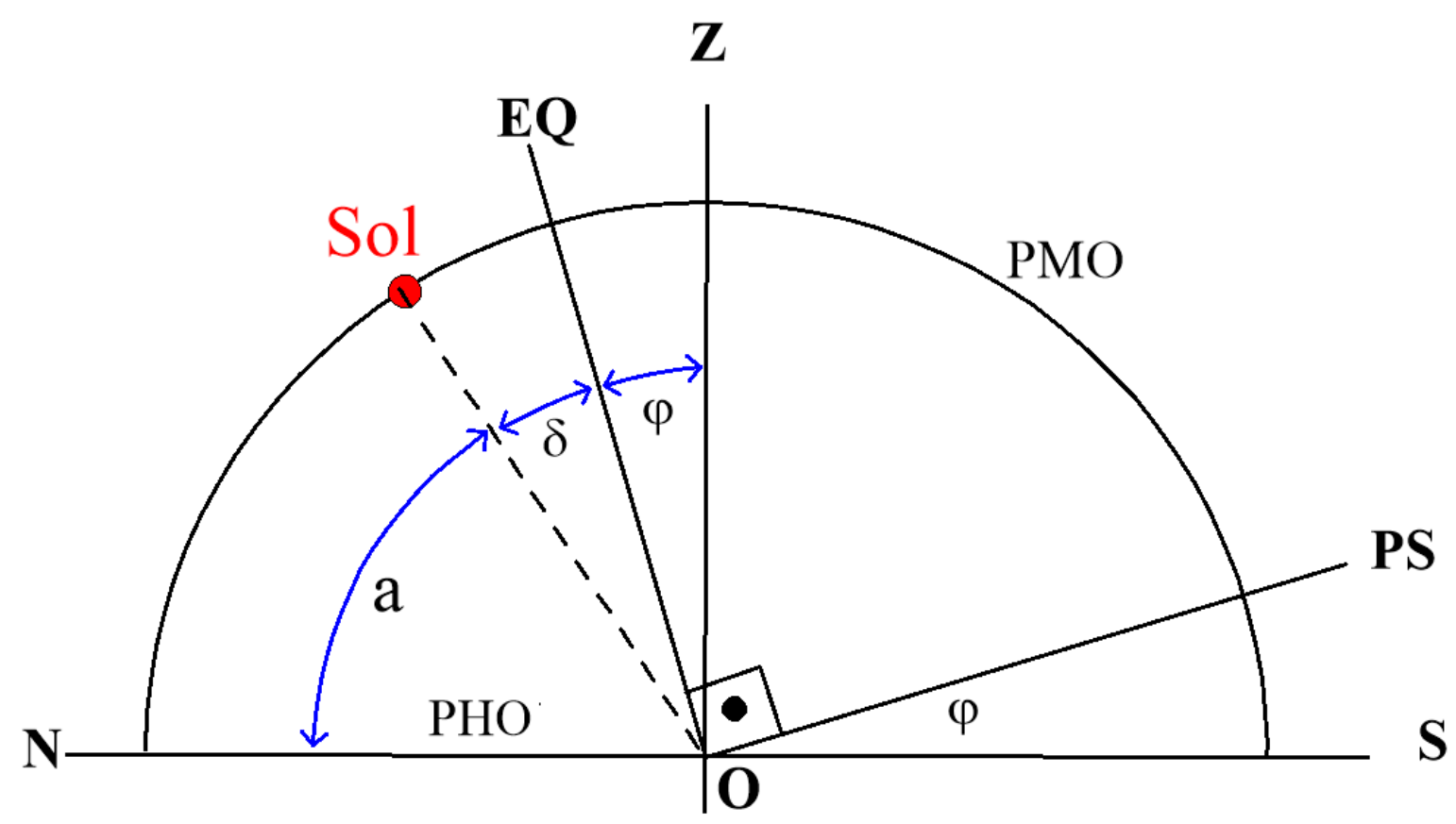

Fonte: Os autores (2020).

Pela figura pode-se ver que a $+\delta+\varphi=90^{\circ}$, valendo portanto a regra do astrolábio para calcular a latitude: $\varphi=90^{\circ}-(\mathrm{a}+\delta)$. A fórmula trabalha em módulo e, portanto, são necessárias quatro regras, para atender às quatro combinações de $\delta \mathrm{e} \varphi$, positivos e negativos. 
Já na operação prática seguiu-se outra ordem: em campo, com o astrolábio em O visou-se o sol, mediuse o ângulo $a$, que resultou em $56^{\circ}$. Depois, calculou-se a declinação pelas tabelas, obtendo-se o valor $16^{\circ} 51^{\prime}$, que foi arredondado para $17^{\circ}$.

A conta, portanto, fica sendo: $\varphi=90^{\circ}-\left(56^{\circ}+17^{\circ}\right)=17^{\circ}$

À vista dessa conta, pode-se entender melhor o trecho da carta de Mestre João que se repete por comodidade: "tomamos / a altura do Sol ao meio-dia e achamos 56 graus, e a sombra / era setentrional [4], pelo que, segundo as regras do astrolábio [5], julgamos / estar afastados da equinocial por $17^{\circ}$, e por conseguinte estar a / altura do pólo antártico em $17^{\circ}$, segundo é manifesto na / esfera".

Nesse texto, a altura do Sol é o $a$ da fórmula $\left(56^{\circ}\right)$. A expressão "segundo as regras do astrolábio julgamos estar afastados da equinocial por $17^{\circ}$ " corresponde ao cálculo da declinação $\delta$ pelas tabelas: o quanto o sol, na eclíptica, está afastado do plano do equador. O valor $17^{\circ}$ para a declinação é uma aproximação dos $16^{\circ} 51^{\prime}$, como se apontou (arredondamento de 9'). Já a expressão "por conseguinte", corresponde ao cálculo pela regra da esfera, da fórmula (5), acima. Estar a altura do polo antártico a $17^{\circ}$ corresponde ao resultado do cálculo de $\varphi$, ou quanto o PS está acima do horizonte.

Finalmente, pelo esquema da Figura 9 se vê que a sombra, por exemplo de uma haste colocada em O, aponta para o sul, já que o Sol está do lado do norte, confirmando o erro dessa passagem da carta. Finalmente, diga-se que a trajetória do Sol nesse dia seria um trecho de reta, paralelo ao equador, passando pela culminação.

\subsection{A precisão da medida realizada}

O local da medição foi o ilhéu da Coroa Vermelha, Baía Cabrália, Porto Seguro. Baseando-nos nos estudos de Dias (1922) ou Cortesão (1943) sobre o local preciso, em combinação com o Google Earth, encontram-se as coordenada que servirão de referências: latitude $\left(16^{\circ} 20^{\prime} 0.43\right.$ "S, ou -16,3333 $\left.{ }^{\circ}\right)$ e longitude $\left(39^{\circ}\right.$ 0'25.69"O, ou $-39,0070^{\circ}$ ). Estas são coordenadas geográficas e não astronômicas, conceitualmente diferentes das terrestres, mas a diferença numérica é desprezível frente aos demais erros do processo.

A primeira verificação a ser feita é comparar a latitude de referência, $16^{\circ} 20^{\prime}$, com a encontrada $\left(17^{\circ}\right)$, constatando-se um erro ou diferença final de $40^{\prime}$ ou $0,67^{\circ}$. Esse valor pode ser decomposto em duas parcelas calculadas a seguir: a imprecisão da tabela na avaliação de $\delta$ e a imprecisão na medição de $a$ em campo.

Através da calculadora NOAA, já citada, pode-se calcular a declinação do Sol $\delta$ ao meio dia solar, na data da medição, com boa precisão (inferior ao minuto) e assim avaliar o erro ou imprecisão da tabela. E por decorrência, calcular o valor e o erro de $a$. Ou seja, avaliar as duas parcelas de imprecisão.

No formulário on-line dessa calculadora da NOAA (Figura 10) deve-se entrar com a latitude (16,3333) e longitude $(-39,0070)$ e complementar com o fuso horário (-3). A seguir indica-se o dia da medição e, como a calculadora não trabalha com o calendário juliano, entra-se nela com a data no gregoriano retroagido, 7 de maio de 1500 (e não 6, como se viu). Falta ainda fornecer a hora (meio dia solar), o que é feito de forma interativa. Começando com 12:00h no campo hora local (Local Time) a calculadora fornece, entre os resultados, a hora da culminação (11:31:55), no campo Solar Noon, que difere da hora legal. Introduzindo-se esse valor no campo Local Time, o programa calcula o novo Solar Noon e, logo nessa segunda interação os valores convergem, como se vê na figura. O resultado desejado aparece no campo Solar Declination: 16,76 ou $16^{\circ} 45,6^{\prime}$.

Comparando-se esse valor da calculadora NOAA, $16^{\circ} 46^{\prime}$, com o resultado dos cálculos com as tabelas de Zacuto, $16^{\circ} 51^{\prime}$, vê-se que a diferença em $\delta$ é de 5', para menos. Ou seja, a tabela está com valores muito bons para a época. Resta examinar a precisão da medição da altura angular do Sol com o astrolábio.

Para calcular esse valor de $a$, usa-se a expressão (5), transformada na Eq. (6):

$$
a=90^{\circ}-(\varphi+\delta)
$$

A aplicação resulta: $\quad \mathrm{a}=90^{\circ}-\left(16^{\circ} 20^{\prime}+16^{\circ} 46^{\prime}\right)=56^{\circ} 54^{\prime}$, que é muito próximo ao valor $56,92\left(56^{\circ} 55^{\prime}\right)$ fornecido pela calculadora NOAA, no último resultado. Ou seja, a medição do ângulo $a$ está incorreta em 54', quase um grau e, portanto, um pouco mais do que o esperado. Assim, os 40' de diferença compõem-se em 
duas parcelas: esses 54' na leitura do ângulo, para menos (comparando com o valor de campo $56^{\circ}$ ) e $14^{\prime}$ ' para mais, na declinação: 5' de diferença por conta da imprecisão da tabela e os 9' de arredondamento: de $16^{\circ} 51^{\prime}$ para $17^{\circ}$.

Tanto o trabalho clássico de Silva (1922), como o de Moraes (1984) que o resume, mesmo sendo técnicos, não analisam a precisão dessa medição de latitude. Nem se tem notícia de outro trabalho que tenha feito isso, até o presente momento

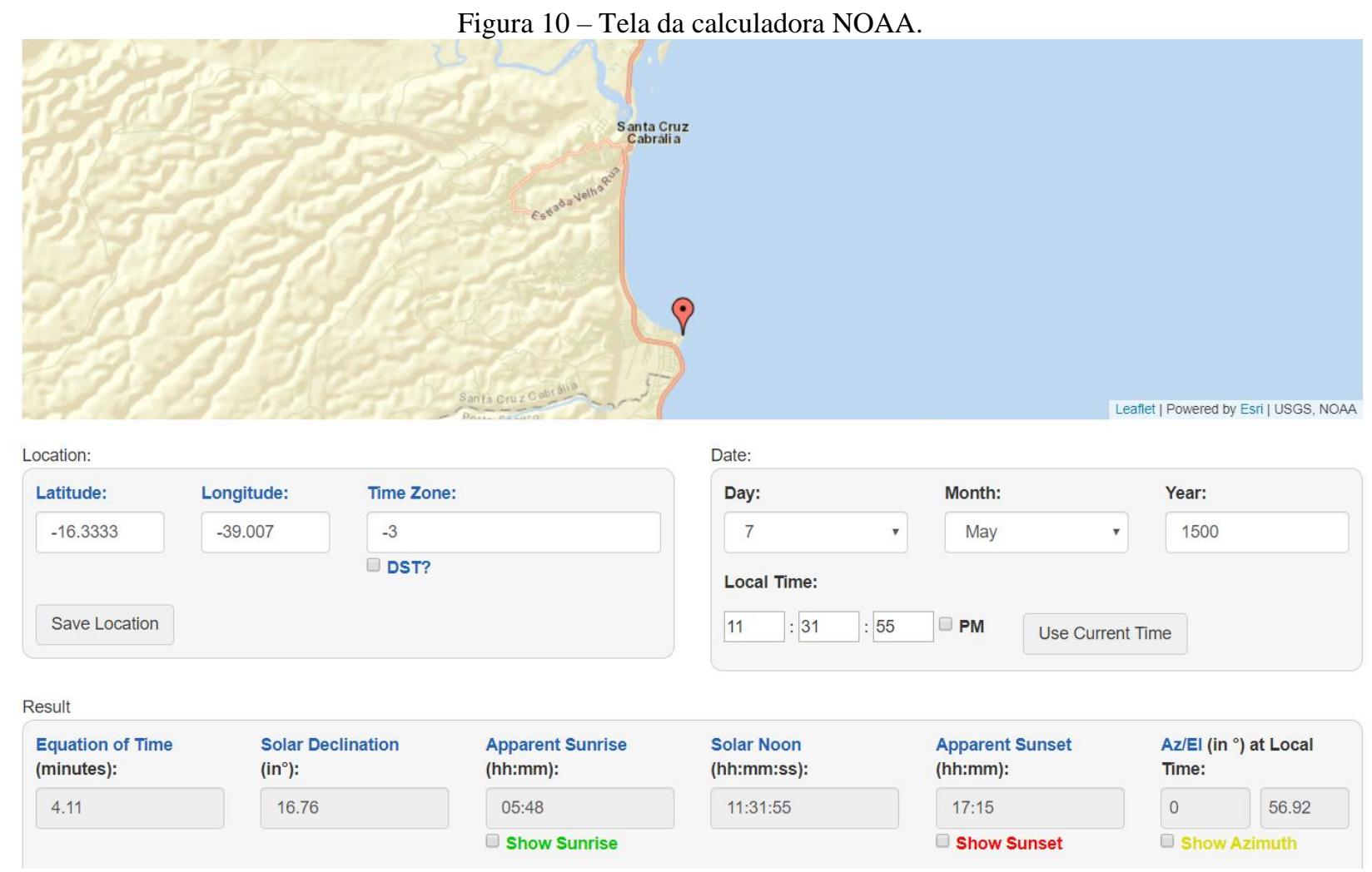

Fonte: NOAA (2020), com dados e mapa customizados pelos autores.

\section{CONCLUSÕES}

Os estudos sobre a reforma do calendário e os cálculos realizados (item 2) permitiram mostrar, por mais de um caminho, dada a sua importância, que a medição da latitude em Porto Seguro, ocorrida a 27 de abril de 1500, no calendário juliano, corresponde na realidade ao dia 7 de maio e não ao 6, no calendário gregoriano retroagido, e embora haja erro neste último, que foi oficializado como Dia do Cartógrafo, sugerese não mudar essa data, mas ter isso em conta para eventuais cálculos, como se fez neste trabalho. Tendo em conta o caráter convencional desse dia, uma mudança desse estilo, traria mais confusão do que benefício. Em todo caso, a Sociedade Brasileira de Cartografia é a instituição mais representativa e competente para deliberar sobre uma eventual mudança.

A análise dessa primeira medição de latitude permitiu reconstituir as operações de campo com astrolábio e os diversos cálculos, coisas que estão subentendidas no texto da Carta de Mestre João. Para isso foi necessário entender a mudança do calendário ocorrida com a reforma gregoriana, bem como compreender como se utilizavam as tabelas para calcular a longitude do Sol na eclíptica e a declinação para cada dia do ano. Foi possível entender e acompanhar as contas que foram feitas em 1500.

Foi possível também avaliar a precisão, tanto da tabela de Abraão Zacuto como da medição de campo. Vale destacar que, desde a Idade Média, se conseguia avaliar bem a duração do ano e a obliquidade da eclíptica com precisão suficiente para construir tabelas precisas para o cálculo da declinação do Sol (erro de 5', no caso concreto) e assim poder determinar a latitude por visada ao Sol, coisa que se fazia necessária quando os portugueses cruzaram o equador e não se via mais a estrela polar.

Finalmente, vale destacar dois pontos, o primeiro é que desde o Concílio de Trento, já se contava com 
regras estabelecer os bissextos, a fim de não defasar o calendário legal do astronômico. E o segundo é que todos os cálculos só foram possíveis graças à disponibilidade de calculadoras siderais que computam a data do equinócio, a declinação do Sol e outras variáveis, em qualquer dia e hora do passado.

\section{Contribuição dos Autores}

O Autor 1 realizou: orientação geral, aspectos históricos, redação, formatação, figuras, conferência de cálculos. O Autor 2 realizou: pesquisas na Internet, tabelas, calculadoras e cálculos.

\section{Conflitos de Interesse}

Os autores declaram que não há conflitos de interesse.

\section{Referências}

AFONSO XI. Libro del saber de astronomia. s/d, 1275 (c). Disponível em: <https://bibliotecadigital.jcyl.es/es/consulta/registro.cmd?id=13284>. Acesso em: 24 ago. 2020.

CINTRA, J. P. As capitanias hereditárias no mapa de Luís Teixeira. Anais do Museu Paulista, São Paulo: v. 23, p. 11-42, 2015. DOI.: 10.1590/1982-02672015v23n0201.

CINTRA, J. P. Reconstruindo o mapa das capitanias hereditárias. Anais do Museu Paulista, São Paulo: v. 21, p. 11-45, 2013. DOI.: 10.1590/S0101-47142013000200002.

COOPER, P.I. The absorption of radiation in solar stills, Solar Energy, Elsevier, Amsterdã: vol. 12, 3, pp. 333 - 346, 1969. DOI.: 10.1016/0038-092X(69)90047-4.

CORTesão, J. A Carta de Pero Vaz de Caminha, com um estudo de Jaime Cortesão. Rio de Janeiro: Livros de Portugal, 1943.

DIAS, C.M. A Semana de Vera Cruz. In Dias, C.M. História da Colonização Portuguesa do Brasil. Porto: Litografia Nacional, 1922. Vol. II, pp. 73-169.

DUARTE, J. F. Notas de astronomia de campo. Rio de Janeiro: s/d, 1955.

FOURMILAB, 2020. Calculadora para a transformação entre dia juliano e gregoriano e outros calendários. Disponível em: <http://www.fourmilab.ch/documents/calendar/>. Acesso em: 24 ago. 2020.

GREGÓRIO XIII, 1582. Bula Inter gravíssimas. Disponível em latim: <https://la.wikisource.org/wiki/Inter_Gravissimas> e em inglês: 〈https://en.wikisource.org/?curid=566140>. Acesso em: 24 ago. 2020.

MEGA ARQUIVO, 2020. 8241- $O$ Astrolábio. Disponível em https://megaarquivo.wordpress.com/2013/05/20/8241-o-astrolabio/. Acesso em: 13 set. 2020.

MORAES, A. de. A Astronomia no Brasil. São Paulo: Edição da Universidade de São Paulo, Instituto Astronômico e Geofísico, 1984.

NOAA, 2020. Calculadora da declinação, da hora da culminação, da altura e outros dados. Disponível em: <https://www.esrl.noaa.gov/gmd/grad/solcalc/index.html>. Acesso em: 24 ago. 2020.

OLIVEIRA, C. de. Dicionário Cartográfico. Rio de Janeiro: IBGE, 1980.

PEREIRA, P. R. Os três únicos testemunhos do descobrimento do Brasil. Rio de Janeiro: Lacerda Editores, 1999.

Revista do Instituto Histórico e Geográfico Brasileiro, “Carta do Mestre João...”, tomo V, n. 19, p. 364366, Rio de Janeiro, $1834 . \quad$ Disponível em: <https://drive.google.com/file/d/0B_G9pg7CxKSsTi1xM3dEZHRldlE/view>. Acesso em: 13 set. 2020.

RIO, Pedro del. Compendio metódico y claro del cómputo eclesiástico antiguo y moderno. s/d, 1790. Disponível em: https://play.google.com/books/reader?id=KZ9hZ52mpQMC\&hl=pt\&pg=GBS.PR29. 
Acesso em: 24 ago. 2020.

SACROBOSCO, Johannes de. Tratado da esfera. Tradução de Pedro Nunes; atualização e notas de Carlos Ziller Camenietzki. São Paulo: Unesp / Nova Stella / MAST, 1991.

SBC - Sociedade Brasileira de Cartografia, Revista Brasileira de Cartografia. Rio de Janeiro, n. 9, ano 4, p. 3, jan-abr de 1973.

SILVA, L. P. da. A arte de navegar dos portugueses. In Dias, C.M. História da Colonização Portuguesa no Brasil, Porto: Litografia Nacional, 1921. vol. I, p. 27-104.

TIME AND DATE (2020). Calculadora do dia do equinócio. Disponível em: <https://www.timeanddate.com/astronomy/tropical-year.html>. Acesso em: 24 ago. 2020.

TORRE DO TOMBO. Documentos: PT-TT-CC-1-2_m0023 e PT-TT-CC-1-2_m0024. Disponível em <https://digitarq.arquivos.pt/viewer?id=3813442>. Acesso em: 24 ago. 2020.

ZACUTO, A. Almanach perpetuum / [trad. lat.] José Vizinho. - Leiria: Abraão d' Ortas, 1496. Disponível em: <http://purl.pt/22001>. Acesso em: 24 ago. 2020.

\section{Biografia do autor principal}

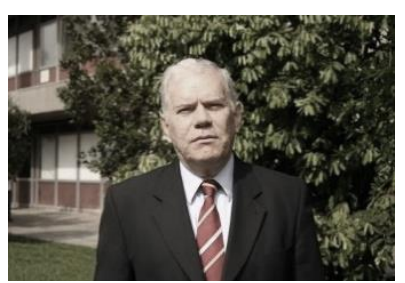

Jorge Pimentel Cintra. São Paulo, 1951. Doutor em Engenharia Civil e Urbanismo. Professor Titular. Docente do Museu Paulista e da Escola Politécnica da USP. Professor de Cartografia Digital, História da Cartografia no Brasil e em São Paulo.

Esta obra está licenciada com uma Licença Creative Commons Atribuição 4.0 Internacional - CC BY. Esta licença permite que outros distribuam, remixem, adaptem e criem a partir do seu trabalho, mesmo para fins comerciais, desde que lhe atribuam o devido crédito pela criação original. 